\title{
Nathan S. Lewis to Give Plenary Address at 2007 MRS Spring Meeting
}

Nathan S. Lewis, George L. Argyros Professor of Chemistry at the California Institute of Technology, will give the plenary address at the 2007 Materials Research Society Spring Meeting to be held April 9-13 in San Francisco. The plenary and awards session will be held Wednesday, April 11, at 6:00 p.m. Lewis's topic will be "Scientific Challenges in Sustainable Energy Technology."

Lewis's research interests include lightinduced electron transfer reactions, both at surfaces and in transition metal complexes, surface chemistry and photochemistry of semiconductor/liquid interfaces, novel uses of conducting organic polymers and polymer/conductor composites, and development of sensor arrays that use pattern recognition algorithms to identify odorants, mimicking the mammalian olfaction process.

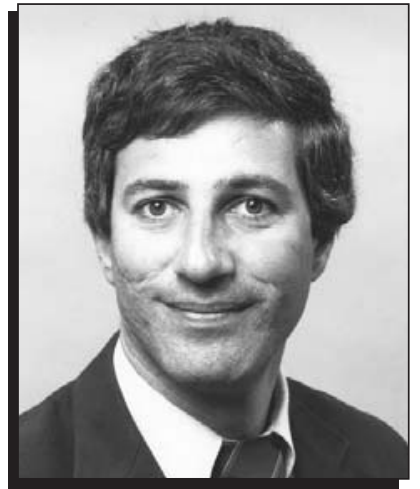

Nathan S. Lewis

Lewis has been on the faculty at Caltech since 1988 and has served as professor since 1991. He has also served as the Principal Investigator of the Beckman
Institute Molecular Materials Resource Center at Caltech since 1992. From 1981 to 1986, he was on the faculty at Stanford University. Just prior to that, he received his PhD degree in chemistry (1981) from the Massachusetts Institute of Technology; he had received his BS and MS degrees from Caltech.

Lewis has been an Alfred P. Sloan Fellow, a Camille and Henry Dreyfus Teacher-Scholar, and a Presidential Young Investigator. He received the Fresenius Award in 1990, the American Chemistry Society Award in Pure Chemistry in 1991, the Orton Memorial Lecture award in 2003, and the Princeton Environmental Award in 2003. He has published over 200 papers and has supervised approximately 50 graduate students and postdoctoral associates.

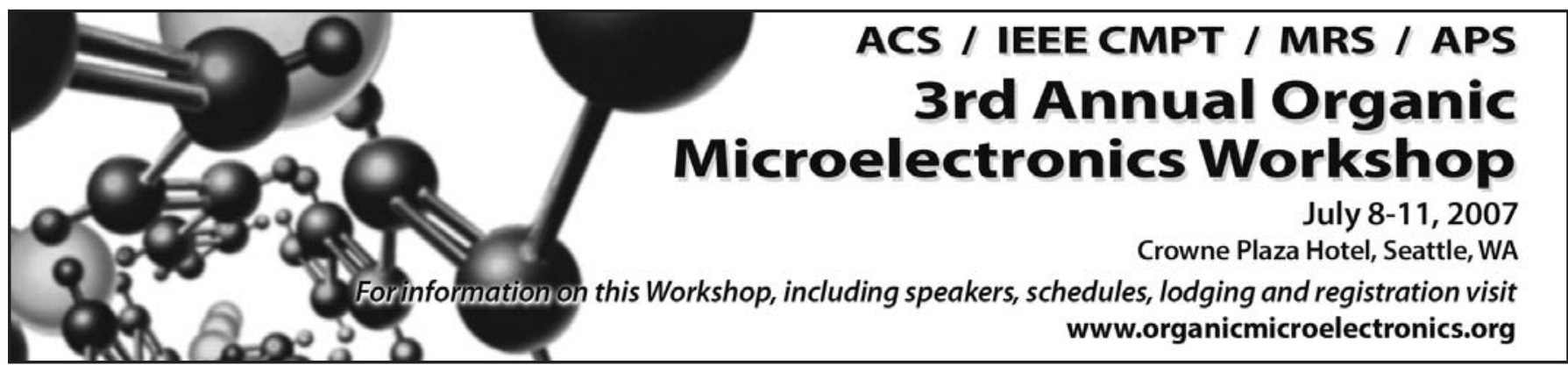

